\title{
The Riddle of the Crosses: The Crusaders in the Holy Sepulchre
}

\author{
Moshe Caine \\ Hadassah Academic \\ College \\ Jerusalem, Israel \\ mosheca@hadassah.ac.il
}

\author{
Doron Altaratz \\ Hadassah Academic \\ College \\ Jerusalem, Israel \\ doronal@hadassah.ac.il
}

\author{
Lindsay MacDonald \\ University College of London \\ London \\ United Kingdom \\ ucfslwm@ucl.ac.uk
}

\author{
Amit Reem \\ Israel Antiquities \\ Authority \\ Jerusalem, Israel \\ amitbaldwin@gmail.com
}

\begin{abstract}
This paper describes the rationale, the challenges and the imaging solutions employed in an attempt to uncover a centuries-old riddle. We suggest an answer to the meaning of the hundreds of crosses, inscribed on the walls and behind the altar of the Chapel of Saint Helena, within the Church of The Holy Sepulchre in Jerusalem. Traditionally, these crosses have been ascribed to the Crusaders of the 12th and 13th centuries, but our research suggests a different chronology. A variety of photographic and photogrammetric imaging technologies have been utilised, along with traditional archaeological research, in an intensive attempt to document as much empirical data as possible during a short period when renovations to the chapel created a small window of opportunity for access. Despite considerable difficulties relating to time and location, three primary goals were set: (1) to capture a 3D representation of the curvature and depth information of the walls covering an overall high-resolution grid of all the stones behind the two central apses; (2) to make a detailed RTI representation of selected stones; and (3) to analyse the chiselling technique of the crosses and decipher the inscriptions and heraldic symbols found near the inscriptions. Three main imaging techniques were employed: 2D panoramic high-resolution Gigapan photography, 3D photogrammetry, and Reflectance Transformation Imaging. The results of the data collected are currently undergoing analysis in an attempt to establish the chronology, typology, and stratigraphy of the incisions. We hope that this will assist in confirming, correcting or rejecting the traditional explanations ascribing the graffiti crosses to the Crusader period. Analysis of the chiselled incisions on the stone reveals regular V-profile grooves. The angles are determined by using a photometric stereo ('shape from shading') image processing technique to determine the surface normal-vectors at each pixel position. Issues relating to the non-ideal 'realworld' conditions of capturing the images will be discussed, including camera movement, ambient light, and accuracy of light position coordinates from the highlights on the billiard ball.
\end{abstract}

Jerusalem. Church. Chapel. St Helena. Crusaders. Crosses. RTI. Photogrammetry. Gigapan.

\section{INTRODUCTION}

The story of the Crusades in Jerusalem is a fascinating mix of truth and fable. Historical data of their beliefs, motivations, travels, and their actions in the Holy Land is plentiful. During the centuries since their exit from the theatre of history, fact and fiction have become interwoven. The lines between piety and greed, asceticism and plundering have blurred, and much of their daily existence remains a riddle until today.

We know of the period between the end of the $11^{\text {th }}$ and the $13^{\text {th }}$ centuries, during which the Crusaders travelled to the Holy Land and centred in Jerusalem, claiming it from the hands of the Muslims. The holiest site for Christianity, then as indeed today, was the Church of the Holy
Sepulchre in Jerusalem, where Jesus was crucified at Calvary and where he is said to have been buried and resurrected. Today, true to its name, the compound of the Church is mired in a complex and complicated arrangement, shared between several Christian denominations, primarily the Greek Orthodox, Armenian Orthodox and Roman Catholic, the Egyptian Copts, Syriacs and the Ethiopians.

The First Crusade was seen as an armed pilgrimage to the Church of the Holy Sepulchre, regarded by all crusaders as an essential act of devotion and even possibly a fundamental duty. During this period, a cistern under the main church was thought to have been the location where Helena, the mother of Constantine the Emperor, had found the True Cross. The area was thus 
widened and transformed into the Chapel of Saint Helena. The Chapel is one of the most intriguing parts of the church, an underground structure located on the eastern side. Historical accounts from the 9-10th centuries relate the place to the invention of the cross. Its dark and gloomy atmosphere adds to the mystery of the site and amplifies the traditions and legends concerning this part of the church.

During the Crusader period, probably in the first half of the 12th century, it was modified to a threeaisled domed structure. Prominent elements of the Crusader church are the two built apses abutting to what remained from the impressive Constantinian stylobate walls. From the southeast corner, a system of stairs was added leading down to the underground cave. In ancient times the cave was part of an Iron-age quarry and a Roman cistern. The apsidal upper level of the church is dedicated to St Helena, who according to the legend personally supervised the mission of excavating the cave and revealing the true cross (Gibson \& Taylor 1994, pp.7-24, 83-84; Pringle 2007, pp.44-45).

Today, when entering the Chapel, one is struck by the dramatic sight of literally hundreds of crosses engraved into the walls of the stairway leading to the underground medieval chambers. Researchers and local tradition are unanimous that these crosses were the graffiti made by Crusader pilgrims. Recent renovation works undertaken in the Chapel of St Helena by the Armenian Church have allowed us a unique opportunity to access the area behind the altar. There, on the walls of the two original apses from the Crusader period, hundreds of additional engraved crosses were revealed, in a great variety of patterns, shapes, and sizes (Figure 2). Another exciting discovery was the presence of numerous Armenian inscriptions, heraldic shields, and other visual symbols, spread all over the wall.

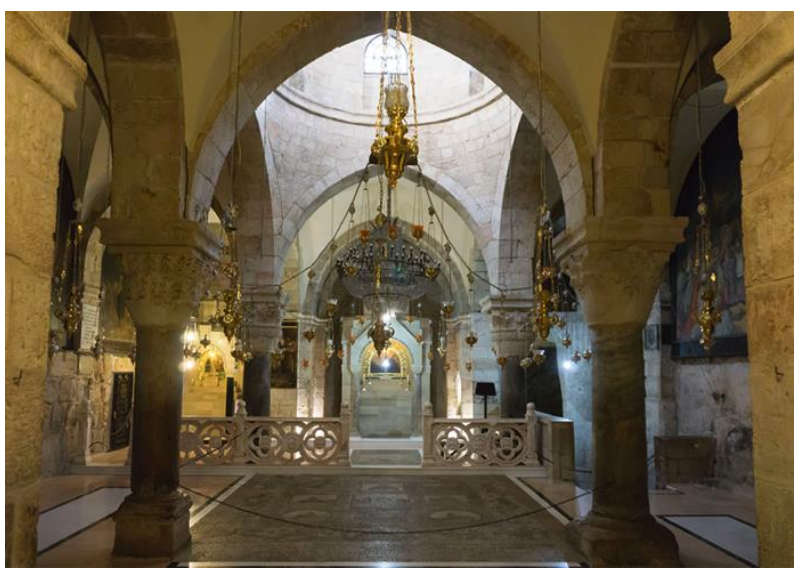

Figure 1: Chapel of Saint Helena, Jerusalem.

\section{THE RESEARCH}

Although there is extensive scholarly literature, dedicated to ancient Christian pilgrimage to Jerusalem, the phenomenon has in the past mainly been studied from historical, sociological and literary perspectives. Little has been written on the archaeological aspects of the pilgrimage, and almost nothing on its material evidence. Therefore, the origin, date and function of these crosses remain enigmatic.

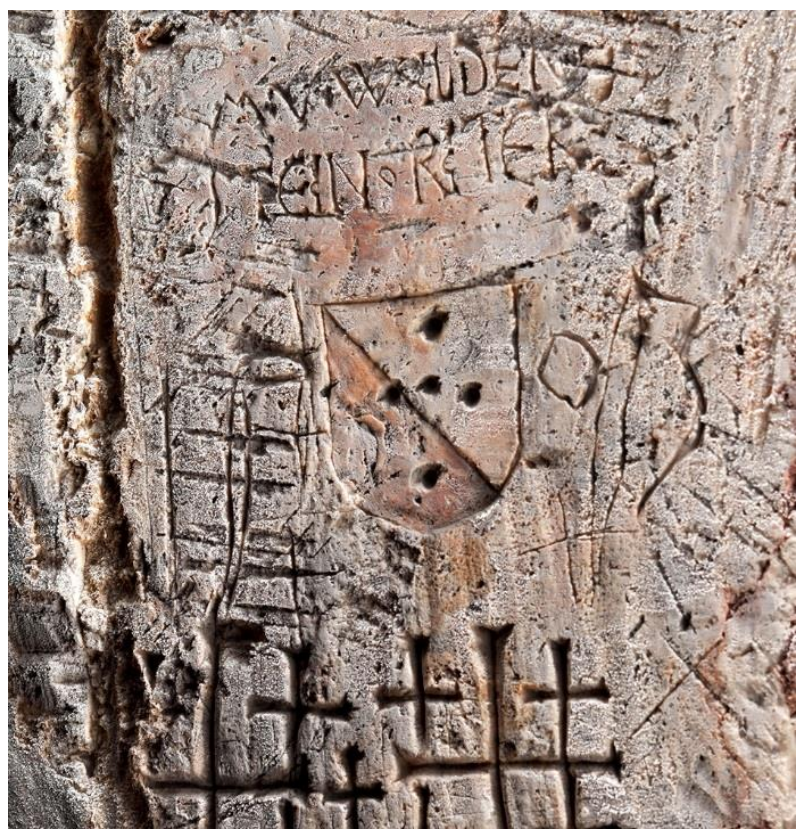

Figure 2: Crosses, inscriptions and herald on wall.

Using the momentum of the crosses' exposure has given a rare opportunity to attempt to establish the chronology, typology, and stratigraphy of the incisions, to confirm, correct or reject the traditional explanation, which ascribes the graffiti crosses to the Crusader period. It has also provided a chance to examine, interpret the finds and to establish their function: were these graffiti made randomly by different pilgrims, or was the engraving of the crosses perhaps an established ritual action, authorised by the church?

Researching all the data is a long and painstaking process. However, we can already claim that, by using traditional archaeological procedures alongside advanced cultural heritage imaging techniques, it is reasonable to identify the crosses as a late medieval creation (not from the time of the Crusaders) and to show that the crosses have deep ceremonial and ritualistic meaning.

\subsection{Research aims}

The primary research objectives of this project were: 
(a) To establish the chronology, typology, and stratigraphy of the incisions.

(b) To confirm, correct or reject the traditional explanation ascribing the graffiti crosses to the Crusader period.

(c) To investigate whether these graffiti were made randomly by different pilgrims, or, perhaps, the engraving of the crosses was an established ritual action, authorised by the church.

Ongoing research is currently underway, comparing the inscriptions on this church with others in various parts of the region, calling into question previous assumptions about their origins. Results of this research will be presented in a future publication.

\subsection{Imaging and photography}

This paper concentrates on aspects surrounding the $3 \mathrm{D}$ digitisation and imaging of the walls and inscriptions. As such, no attempt is made here to present conclusions or to propose archaeologically based theories regarding the wherefore or the why of the unique phenomenon of the crosses. The focus of this work remains in the application of cultural heritage imaging technologies and their hoped-for outcomes. Several considerations determined the photographic solutions to the documentation task:

\subsection{Time schedule}

All imaging had to be undertaken during an extremely narrow 'window of opportunity', during a particular stage of the renovations. Furthermore, the fragile inter-denominational tensions between the various custodians of the Church meant that at any specific moment we could be requested to leave. The demand for our departure indeed happened on more than one occasion. In all, this allowed us a maximum of two full working days.

\subsection{Location}

Working conditions in the chapel were challenging The primary work area, the two apses behind the altar, is very narrow, between $30-100 \mathrm{~cm}$ wide. The height of the walls exceeds three metres, and the light level is low. Furthermore, the electricity supply was insufficient; this meant that we were dependent entirely on small portable light sources. In our case a battery-powered $12 \times 16 \mathrm{~cm}$ LED light and small infrared-controlled flash lighting. Strict regulations prohibited the bringing in of heavy equipment, large tripods or even a small ladder. Thus, all photographic work had to be done with small-scale portable gear. The equipment included: two Nikon DSLR and one Sony mirrorless camera, three small tripods (one for the RTI), two laptops to control the tethered shooting. Direct on-site evaluation and feedback were essential, as there was no room for error or time for reshooting.

\subsection{Budgets}

As with numerous cases in projects like these, funds were limited, which in turn limited the resources, both technical and human.

\subsection{Defining the needs}

The area of interest in the chapel was centred on the two semi-hemispherical walls of the north and south apses located behind the main altar of Saint Helena (Figure 3). These are formed of hundreds of stones, approximately $30-50 \mathrm{~cm}$. in size, densely inscribed with crosses, symbols, coats of arms and inscriptions in various levels of clarity. Also, some walls around the apses and walls on either side of the staircase leading down to the chapel are inscribed, albeit to a lesser extent. It was the intention of this project to gather as much data from the stones as possible in the short time available so that the results can be made accessible to lengthy and convenient research, post-factum.

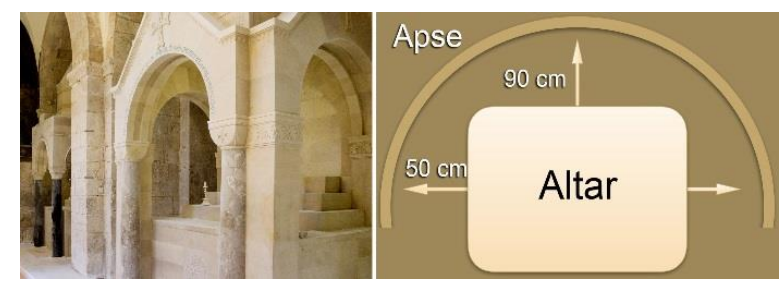

Figure 3: Altars and Apse dimensions.

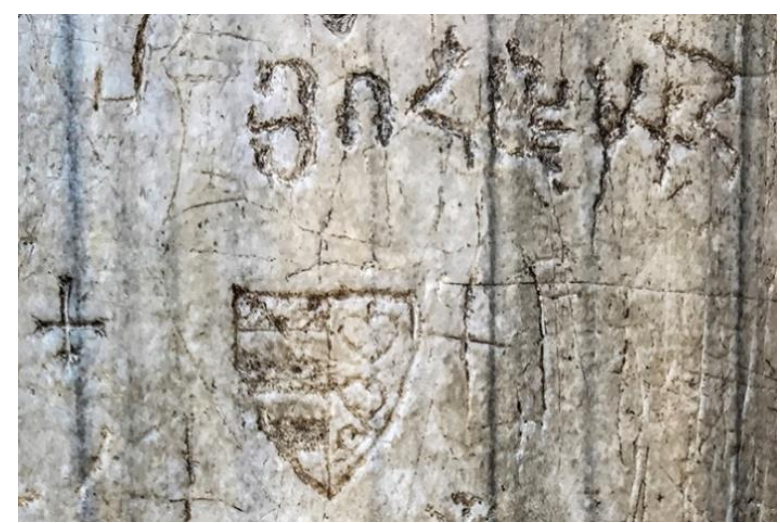

Figure 4: Detail of pillar at Church entrance.

During scouting visits to the location, additional inscriptions were noticed on the marble pillars and the wooden door at the entrance to the church (Figure 4). It was decided to image these also.

\section{THE CHALLENGE}

The main hurdle inherent in this task lay in the conflict between two equal needs. On the one 
hand, that of extremely high-resolution close-up imaging of all the stones, in some cases of small areas within them, in such a way as to bring out as much of the inscribed detail as possible. On the other hand, it was also necessary to locate each stone in relation to the others, i.e. to map out an entire grid of the walls and apses. The intention of mapping would have required shooting from a location where the whole apse could be covered in a single high-resolution or tiled shot. The initial concept was to shoot the walls with a Gigapan robot (http://www.gigapan.com) at the highest possible resolution. This proved impossible, however, due to the extremely short shooting distance, sometimes no more than $30 \mathrm{~cm}$.

\section{IMAGING TECHNOLOGIES}

Following several scouting tours to understand the nature of the task, the difficulties and the needs, three prime photographic technologies were chosen. These were: Gigapixel photography, Photogrammetry, and RTI.

\subsection{Flat Gigapixel panorama}

\subsubsection{Theory}

A Gigapixel image is a digital image bitmap composed of one billion pixels $(1,000$ megapixels. This massive image usually contains anywhere between tens and thousands of individual overlapping photos, stitched together by proprietary software to form a single ultra-high resolution picture. Several technologies and systems are in use today, ranging from complex and expensive to cheap and simple:

- Zoomify (http://www.zoomify.com/)

- PTgui (https://www.ptgui.com/)

- Gigapan (http://www.gigapan.com/)

- Kolor Autopano (http://www.kolor.com/autopano/)

The Gigapixel image technology is in fact two separate technologies: one for stitching and composing the image, the other for its display. The stitching process involves sophisticated algorithms for image registration, calibration and alignment, blending, normalising, tone and colour correction, masking, sharpening and finally projection in various formats: Rectilinear, Cylindrical, Spherical, Cubic, Mercator, and Equirectangular.

While these extensive images are fantastic for large-scale prints, their large file size makes them impractical for online viewing. To overcome this problem, most viewer technologies take a 'pyramidal' approach, i.e. dicing an image into many pieces or 'tiles', as in a mosaic. Zoomify performs this dicing on many versions of the image, each at a different resolution or size. The result is a pyramid of tiles, within which a website visitor can navigate to view any part of the image at any level of zoom. Viewing is fast and responsive because each view involves the download of only a small number of image tiles, each of which is very small in size.

\subsubsection{Practice}

As stated, a single, sequential panoramic image was not possible due to distance limitations. Also, even if it were possible, such images would most likely have introduced progressive geometric distortions as the focal point moved away from the centre. Thus, a systematic, sequential shooting of every stone was performed at high resolution and with RAW file format. This process was carried out with extreme care to maintain as closely as possible consistency in shooting distance, oblique lighting, and sequence. In this way, each apse was later reconstructed as a flat, two-dimensional highresolution representation (Figure 5 ), with each file weighing in at approximately 2 Gigabytes. To allow for easy access, viewing and tagging of these extremely large files, they were uploaded to a private Gigapan gallery, accessible to the IAA researchers. (See link below.)

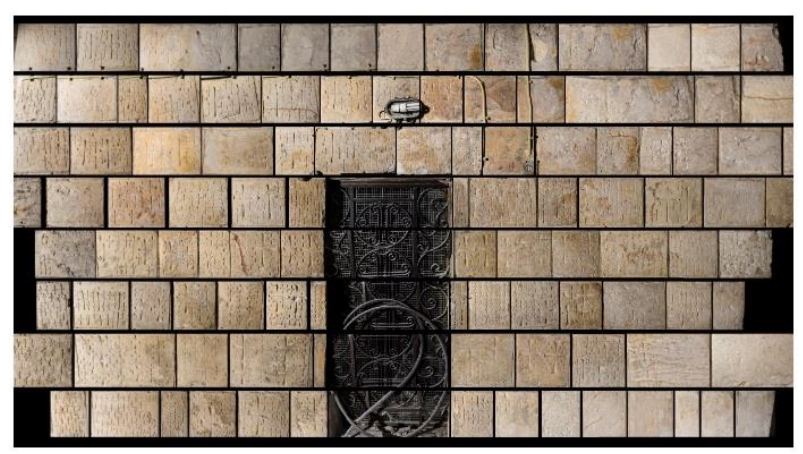

Figure 5: Gigapixel grid of South Apse.

\subsection{Photogrammetry}

\subsubsection{Theory}

Photogrammetry is the "science of measurement in photos", and is most commonly used in remote sensing, aerial photography, archaeology, architecture and other fields where we need to determine measurements from photographs. It is based on the principle that while a single photograph can only yield two-dimensional coordinates, height and width (X-Y), two overlapping images of the same scene, taken slightly apart from each other (a stereo pair) can allow the third dimension $(Z)$ to be calculated through the process of triangulation.

A photogrammetric model combines the elements of shape, texture and, lighting of the object and stores them as a combined vector and raster file, thereby providing the combined advantages of mathematical accuracy and flexibility, along with 
photographic exactitude of colour and texture. This process lends itself especially to 3D reproduction and representation of existing real objects and surfaces, rather than the creation process of new objects, based on copying or imagination. Industrial objects, museum artefacts, merchandise, buildings, even people can be represented in this way.

Recent years have seen a significant advancement in this field, due both to improvements in algorithms and software, as well as the proliferation of highquality DSLR cameras and high-end phone cameras. Consequently today, there is a growing argument that for many purposes, 3D digitisation by image-based photogrammetry can equal and often surpass laser and structured-light imaging (Skarlatos \& Kiparissi 2012). Moreover, Pavelka argues that with good configuration and quality photos taken by digital camera, the accuracy (standard deviation) reaches from 0.2 to $1 \mathrm{~mm}$ from distances 1-5 metres. For larger and more distant objects the accuracy is worse but still acceptable for many purposes (Pavelka et al. 2013). Thus photogrammetry-based 3D imaging has moved from the status of low cost/low quality to that which challenges the quality of mid to high-end scanners in certain fields (Cultural Heritage Imaging 2015).

\subsubsection{Practice}

Taking pictures of the apses and walls with overlapping coverage and consistent lighting allowed us to reconstruct three-dimensional models of the structures (Figure 6). This process was by no means an easy task, nor, in truth, an entirely successful one. Whereas quick low-resolution tests were carried out on location, following completion of the photography on site, all post-processing was performed at the studio. The processing was attempted in parallel with four photogrammetry software packages:

- $\quad$ Agisoft Photoscan (http://www.agisoft.com)

- Autodesk Remake (discontinued)

- Autodesk Recap 360 (https://www.autodesk.com/products/recap/)

- 3D SOM (http://www.3dsom.com)

Each software package has its advantages and disadvantages regarding speed, accuracy, and flexibility to overcome shooting faults, hardware demands and so forth. Subsequently, it transpired that the best results were achieved overall with Agisoft Photoscan, though in some cases Autodesk proved equal to the task.

Once again, due to the subsequent file size of the photogrammetric models and the need for the researchers to access the models with ease and furthermore to annotate them with their findings, it was decided to upload the models to the Sketchfab (https://sketchfab.com) web platform. This excellent site allows for post-processing, lighting, metatagging and annotating the models.

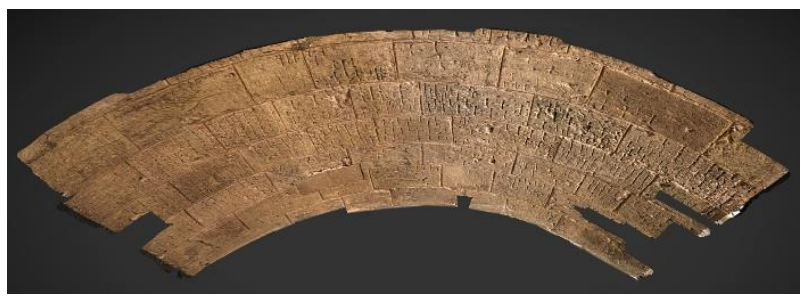

Figure 6: South Apse. Photogrammetric model, showing the curvature of the wall.

\subsection{Reflectance Transformation Imaging (RTI)}

\subsubsection{Theory}

$\mathrm{RTI}$ is a unique digital photographic technique aimed at enhancing the surface detail of objects through an algorithmic rendering of multiple registered digital images of the object, shot with controlled, varying, yet known light positions. Termed initially Polynomial Texture Mapping (PTM), the method was invented by Tom Malzbender at the Hewlett Packard Labs. The seminal paper describing the method was published in 2001 (Malzbender, Gelb \& Wolters 2001). Today the technology continues to be developed and promoted by a dedicated international team, supported by the Cultural Heritage Imaging Corporation $(\mathrm{CHI})$.

The power and beauty of RTI are in its ability to enhance the surface-detail of a wide variety of materials by changing the apparent direction of light falling upon it. This 'relighting' is done after the photographic session has been completed, and at the leisure of the researcher in the comfort of the laboratory.

During photography, the light sources are positioned at a constant radius from the subject and surround it at incremental angles, forming a dome or hemisphere of light positions.

There are two basic methods for creating RTI images: the Highlight Method and the Dome Method. Typically 40 to 70 photographs are taken and imported into software, which calculates the light positions (LP file) and forms the basis for the generation of the final PTM file, enabling viewing by a virtual light source. The final image, viewed with a Java-based viewer (RTI viewer), initially looks like a flat, standard photograph. However, it offers the ability to move the virtual light source interactively around the image in a manner similar to a 'virtual torch' (MacDonald 2011). The user may also zoom in and out, change sharpness, contrast and other light and surface properties, through a series of real-time filters, thus often revealing surface details not visible to the naked eye under normal viewing 
conditions. Screen snapshots can be recorded as jpeg images whenever the user wishes.

\subsubsection{Practice}

As we shall see in the tests carried out here, the $\mathrm{RTI}$ technology is very flexible, relatively easy to master and yields remarkable results (Figure 7). Though relatively cheap and straightforward, it is nevertheless time-consuming and demands total accuracy in execution. These two demands tended to fly in the face of the reality when working in the chapel. Time was short, and shooting conditions placed a high burden on the requirements for accuracy. Nevertheless, in consultation with the chief archaeologists, 25 stones were earmarked for $\mathrm{RTI}$ imaging. Once again, this was done at the highest possible resolution available on site and resulted in files of approximately 200 megabytes each. Processed by the highlight-RTI method, the results allow for standard, specular, and normals viewing as well as bookmarking of lighting directions, filtering and zoom factor. The results of this may be viewed online (http://the-newjerusalem.com/crosses).

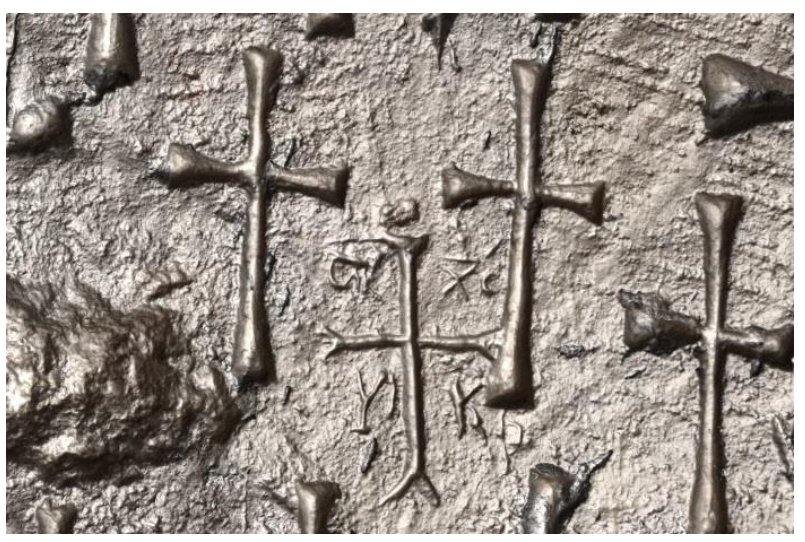

Figure 7: Detail of stone. RTI with Specular Enhancement.

\section{DIFFICULTIES}

As we alluded earlier, whereas the goals were specified and the proposed technological solutions carefully planned, the actual photography on site was fraught with difficulties. Most of these were down to the working conditions. A major part of the chapel renovation involved repaving the floors, which in turn included machine cutting the stones. Consequently, the entire chapel was covered with a thin layer of fine stone powder, which both invaded the equipment and hampered breathing.

The short shooting distance coupled with the large surface areas to be covered demanded the use of wide-angle (short focal length) lenses. However, these would have distorted the image unacceptably. Therefore it was decided to use a slightly telephoto lens $(70 \mathrm{~mm})$ with a coverage somewhat larger than a single stone. These conditions in turn, together with the lack of available light made precise focusing extremely difficult. Autofocus was attempted but also proved unreliable, possibly due to the lack of sufficient texture, coupled with the persistent fine stone dust in the air. Consequently, several areas of the wall suffered from inaccurate focus, which resulted in problems building the dense point clouds and photogrammetric meshes.

Consistency and accuracy of lighting were also more difficult than predicted, primarily due to lack of space, the inability to use ladders or other aids and the difficulty to pre-visualise the results. This was mainly the case with the RTI photography, where it was physically impossible in many cases to maintain accurate and symmetric semihemispherical lighting for successive images. In some cases, this also resulted in slight misregistration in photography, which in turn hampered the mathematical process of calculating shape from shading of the normal.

\subsection{Analysis of 3D point clouds}

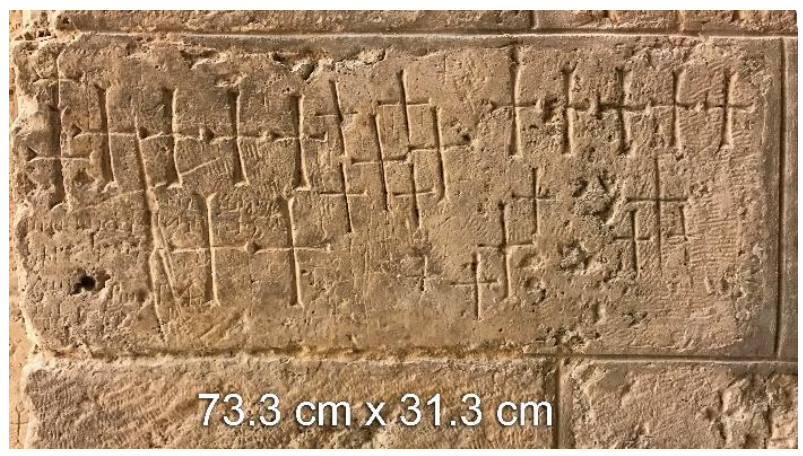

Figure 8: Dimensions of a stone with incised crosses.

The 3D model produced by Agisoft Photoscan from a set of images from differing viewpoints is encoded as a point cloud, in which each point from the dense matching process is represented by a coordinate triplet $(x, y, z)$. The $3 \mathrm{D}$ object is disembodied, in the sense that it floats in space without orientation or scale. Because no scale bar or ruler was included in the scene photos, adjacent to the stone, the scale has to be applied post hoc. Figure 8 shows one of the stones, for which the point cloud contained 649,413 points, and the rendered dimensions of the stone were only 4.64 by $1.98 \mathrm{~mm}$. The actual dimensions of the stone, as measured on site, were 733 by $313 \mathrm{~mm}$ (Figure 8), so a scaling factor of 157.98 was needed to magnify the data points to the true scale.

The point cloud was imported into Matlab for processing. First a plane was fitted to the top surface, using a least-squares regression method, and then the point cloud was rotated by a 3D matrix to align the normal of the fitted plane with the $Z$ axis 
(Rodrigues method). The points were projected onto a $1 \mathrm{~mm}$ grid to produce a digital terrain map of the surface height at each pixel, with 'holes' filled by interpolation of neighbouring values. The resulting image can then be sampled along section lines to show the surface profile (Figure 9).
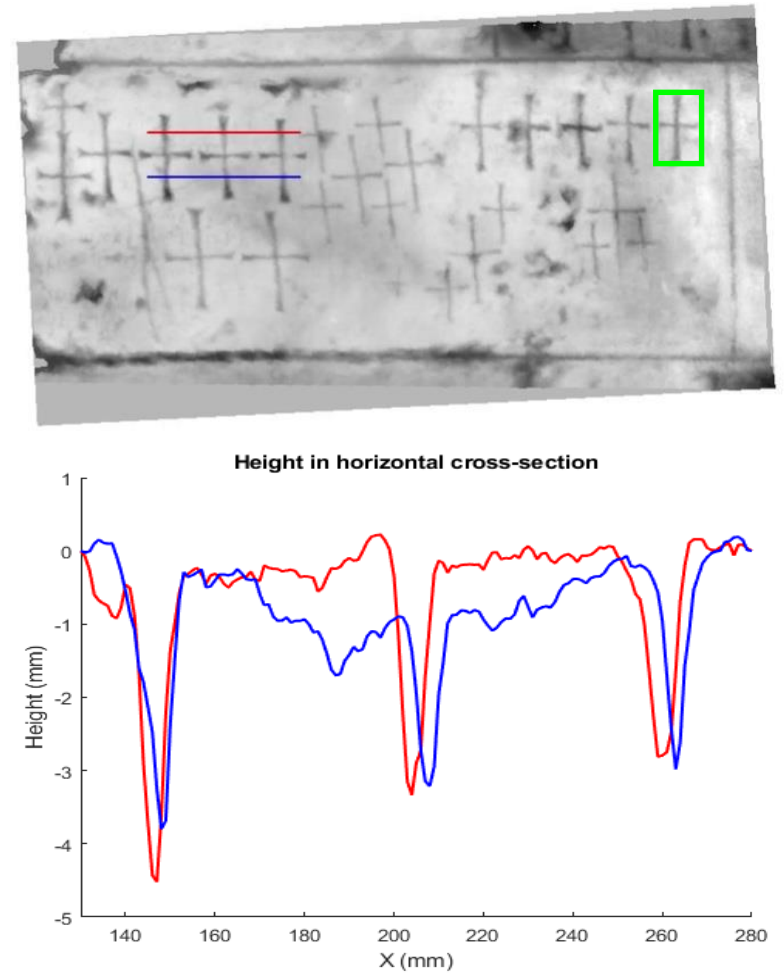

Figure 9: (top) Elevation map showing section lines (red and blue); (bottom) corresponding height profiles.

The incised vertical shafts of the three crosses appear clearly as troughs in the elevation map of Figure 9, with a maximum depth of 3-4 $\mathrm{mm}$. The walls of the troughs are smooth and have similar shapes along both the upper and lower section lines. The profiles are V-shaped, suggesting use of a chisel.

Taking one of the crosses and plotting it in 3D shows the careful and deliberate regularity of its formation (Figure 10). It gives the impression of having been made as an act of devotion, not by a professional mason but by someone with time and motivation and the appropriate tools to leave his mark.

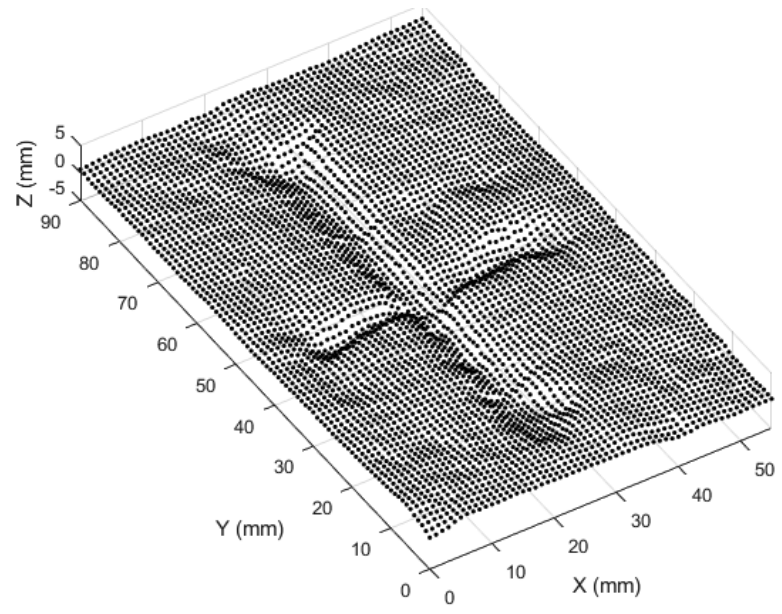

Figure 10: $3 D$ plot of cross at top right of stone in Figure 8.

The regularity of the carving of the stone can be seen by plotting a family of 61 horizontal crosssections at $1 \mathrm{~mm}$ intervals down the cross (Figure 11).

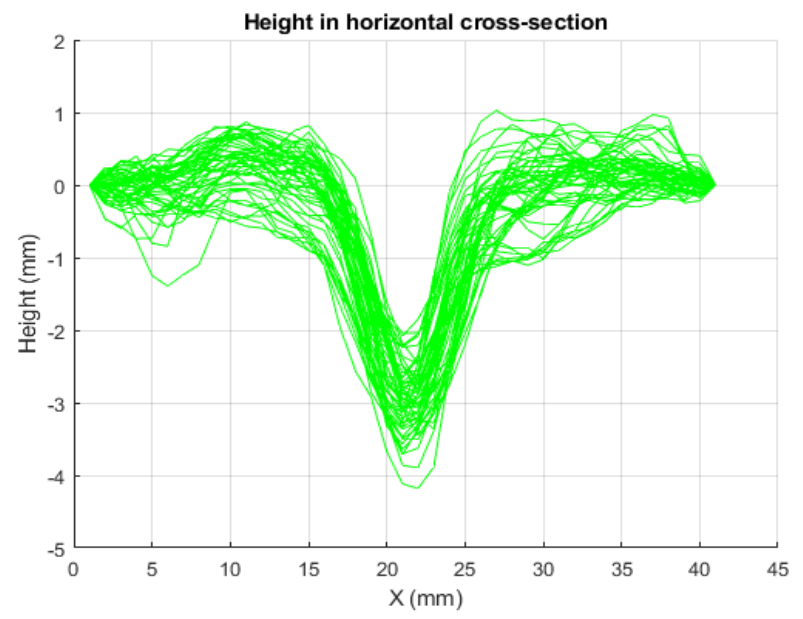

Figure 11: Family of cross sections.

Analysis of this series of profiles reveals that the depth (peak to trough) of the incision remains steady between 2.8 and $4.8 \mathrm{~mm}$. The width of the trough (distance between left and right walls at half depth) ranges from 6 to $11 \mathrm{~mm}$. The angles of the side walls (determined by fitting a tangent line through the wall profile at half depth) are mostly in the range of 15 to 30 degrees. The overall shape is by no means perfect, but the controlled irregularity contributes to the pleasing visual effect.

These imaging and visualisation techniques could be repeated for all of the crosses in each of the stones, to build up statistics of the geometry of the carving throughout the Church. 


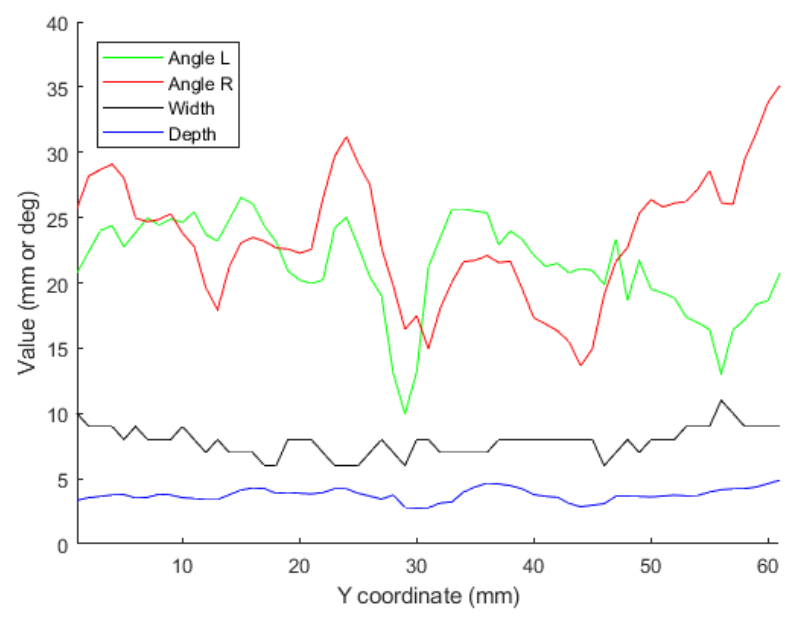

Figure 12: Values of width, depth and angles of walls of series in Figure 11.

\subsection{Analysis of RTI image sets}

An alternative approach to the geometry of the carving is by applying the principles of photometric stereo to compute the surface normal vector at each position from the set of images taken from a fixed viewpoint with directional lighting. The normals give the angles of the faces of the incisions (Figure 13).

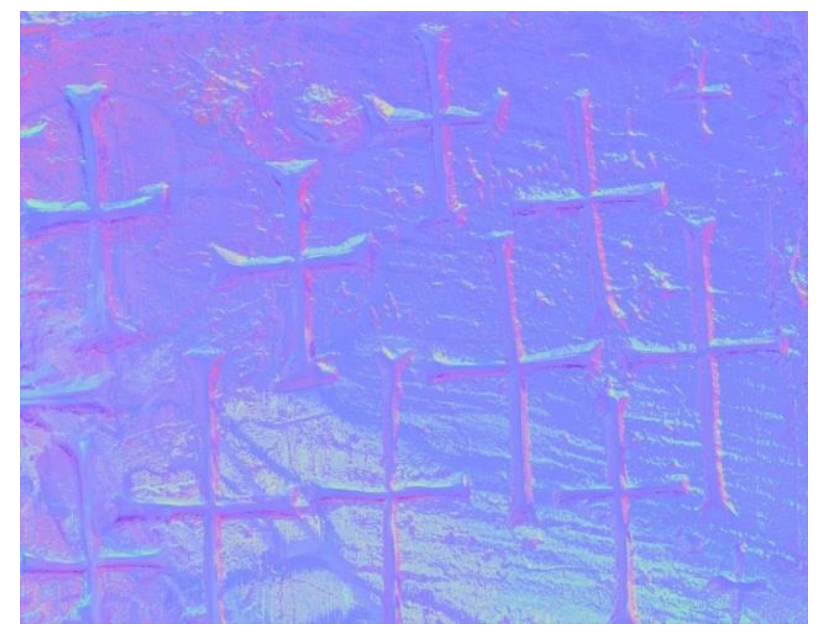

Figure 13: Computed normals from RTI image set.

\section{CONCLUSION}

On-location photography is as much about improvisation as it is about precise, controlled work. Therefore, despite the limitations outlined above, the short and intense work period provided satisfying results. Over two thousand RAW location shots were post-processed and yielded nearly 50 Gigabytes of data. These included 30 highresolution RTI files, approximately 15 3D photogrammetric models, several 2D panoramic grids and hundreds of high-resolution individual stone images. It now remains the task of the archaeologist and researchers to interpret these findings and, so we hope, decipher the "riddle of the crosses".

\section{REFERENCES}

Agisoft Photoscan. http://www.agisoft.com/ (retrieved 24 February 2018).

Atangeo Balancer. http://www.atangeo.com/ (retrieved 25 February 2018).

Herald 3D.

https://sketchfab.com/models/6e4e0aa3359c44fba8f55c3 db0b49b17 (retrieved 24 February 2018).

Gibson, S. and Taylor, J. E. (1994) Beneath the Church of the Holy Sepulchre, Jerusalem: the archaeology and early history of traditional Golgotha (Vol. 1). Palestine Exploration Fund.

Gigapan North Apse, Gigapan North Apse. http://www.gigapan.com/gigapans/202145 (retrieved 25 February 2018).

MacDonald, L. W. (2011) Visualising an Egyptian Artefact in 3D: Comparing RTI with Laser Scanning. Proc. BCS Conf. on Electronic Visualisation and the Arts (EVA), London, July.

Malzbender, T., Gelb, D. and Wolters, H. (2001) Polynomial texture maps, Proc. ACM Siggraph, 28, 519528.

Meshlab. http://meshlab.sourceforge.net/ (retrieved 25 February 2018).

Pavelka, K. et al. (2013) Non-expensive 3D documentation and modelling of historical object and archaeological artefacts using close-range photogrammetry. Geoinformatics FCE, 10, 53-66.

Photogrammetry, $\mathrm{CHI}$. Cultural Heritage Imaging. http://culturalheritageimaging.org/Technologies/Photogra mmetry/ (retrieved 25 February 2018).

Pillar 3D.

https://sketchfab.com/models/52e4d050ac9a4a8f9a282b c4c9f3af81 (retrieved 24 February 2018).

Pringle, D. (2007) The Churches of the Crusader Kingdom of Jerusalem. Vol. III The City of Jerusalem. Cambridge.

RTI Online. http://the-new-jerusalem.com/crosses/ (retrieved 25 February 2018).

Scopigno, R., Callieri, M., Cignoni, P., Corsini, M., Dellepiane, M., Ponchio, F., and Ranzuglia, G. (2011) 3D models for cultural heritage: Beyond plain visualization. Computer, 44(7), 48-55.

Skarlatos, D., and Kiparissi, S. (2012) Comparison of laser scanning, photogrammetry and SFM-MVS pipeline applied in structures and artificial surfaces. Annals of the photogrammetry, remote sensing and spatial information sciences, Volume i-3.

South Apse 3D.

https://sketchfab.com/models/119b8f423a844a25b4e108 cebe4320ac (retrieved 24 February 2018).

Stone 3D.

https://sketchfab.com/models/bd0ł3b9358f64ff2b14406a cbc430080 (retrieved 24 February 2018). 